\title{
A novel cause of late bleeding after lobectomy: Erosion of the bronchial staple line in the chest wall
}

Satoshi Takamori, MD, Hiroyuki Oizumi, PhD, Jun Suzuki, MD, and Mitsuaki Sadahiro, PhD, Yamagata, Japan

From the Faculty of Medicine, Department of Surgery II, Yamagata University, Yamagata, Japan.

Disclosures: The authors reported no conflicts of interest.

The Journal policy requires editors and reviewers to disclose conflicts of interest and to decline handling or reviewing manuscripts for which they may have a conflict of interest. The editors and reviewers of this article have no conflicts of interest.

Received for publication April 30, 2020; revisions received April 30, 2020; accepted for publication May 8, 2020; available ahead of print May 16, 2020.

Address for reprints: Hiroyuki Oizumi, PhD, Faculty of Medicine, Department of Surgery II, Yamagata University, 2-2-2 Iida-Nishi, Yamagata 990-9585, Japan (E-mail: hohizumi@med.id.yamagata-u.ac.jp).

JTCVS Techniques 2020;3:338-40

2666-2507

Copyright (C 2020 The Authors. Published by Elsevier Inc. on behalf of The American Association for Thoracic Surgery. This is an open access article under the CC BY-NC-ND license (http://creativecommons.org/licenses/bync-nd/4.0/).

https://doi.org/10.1016/j.xjtc.2020.05.008

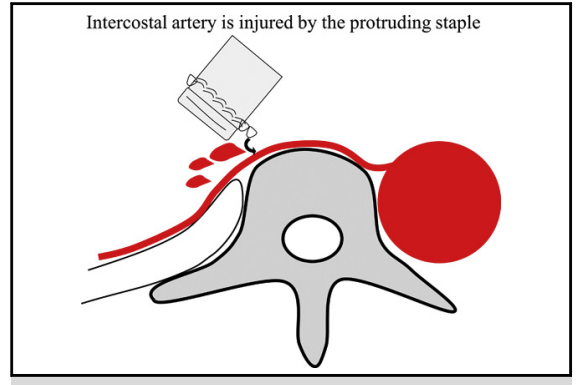

Injured intercostal artery present around the vertebral body due to the protruding staple.

CENTRAL MESSAGE

We present the first report of delayed hemothorax due to bronchial stapling after a right lower lobectomy for lung cancer.

See Commentary on page 341. has not. Here we report a case of delayed hemothorax arising as a complication following the use of bronchial staples.

\section{CASE DESCRIPTION}

A 68-year-old man with lung cancer underwent right lower lobectomy. Surgery was performed using a posterolateral incision and a fifth intercostal thoracotomy. All blood vessels were ligated and dissected. Intraoperatively, a stapler was used at the bronchus and parenchyma to divide the middle and lower lung lobes. Bronchial stapling was done using an Echelon stapler (Ethicon Endo-Surgery, Cincinnati, Ohio) with a gold cartridge. On postoperative day 5 , the pleural effusion was minimal (Figure 1, A); however, while preparing for discharge, the patient experienced hypovolemic shock, with a decrease in systolic blood pressure to as low as $58 \mathrm{~mm} \mathrm{Hg}$. His hemoglobin level was $11.0 \mathrm{~g} /$ $\mathrm{dL}$, but decreased to $7.6 \mathrm{~g} / \mathrm{dL}$ thereafter. Chest roentgenography showed a sudden increase in the amount of right pleural fluid (Figure 1,B).

Emergency thoracotomy was performed following a diagnosis of massive hemothorax, and $2451 \mathrm{~mL}$ of blood was drained. Projectile bleeding was seen from the intercostal artery present around the vertebral body (the segmental artery) in front of the eighth thoracic vertebra. A staple attached to the lower right bronchus stump was facing the vertebral artery. The staple at the end of the staple line was protruding (Figure 2), and we believed that it had injured the inner chest wall due to movement during respiration, causing the bleeding. A $\mathrm{Z}$ suture was applied to the central and peripheral sides of the artery, and the bleeding was stopped. We performed blood transfusion during the surgery using $1120 \mathrm{~mL}$ of red blood concentrate.

Retrospectively, enhanced computed tomography performed before reoperation revealed that the staple was in contact with the artery in front of the thoracic vertebra (Figure 1,C). The postoperative course was uneventful, and the patient was discharged on the fifth postoperative day after the second operation.

The patient provided informed consent for publication of the study data.

\section{DISCUSSION}

Late-onset hemothorax due to misaligned stapling has been reported only rarely. ${ }^{2-5}$ In a study of 2030 patients, 36 $(1.8 \%)$ developed stapling-related complications intraoperatively (31 patients) or postoperatively (5 patients). ${ }^{4}$ Intraoperative complications included air leakage, stapling failure, and bleeding. The incidence of reoperation for stapling-induced postoperative bleeding was $0.3 \%$ (4 of 1143 operations), and bronchial stapling caused hemothorax in only 1 of the 2030 patients who underwent surgery. Although hemothorax from an intercostal or inner thoracic artery injury caused by the staple on the edge of the lung 

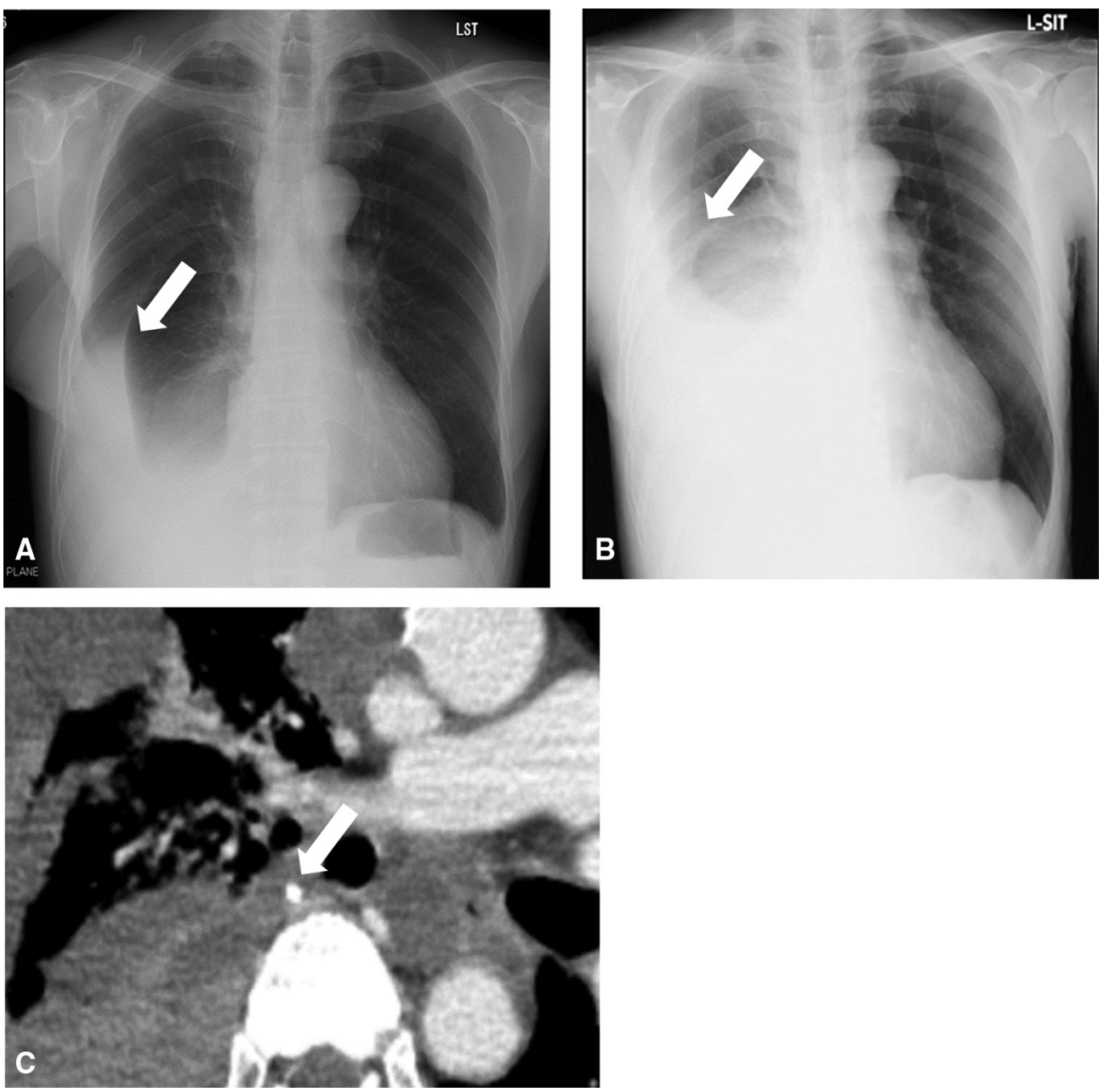

FIGURE 1. A, Roentgenography on postoperative day 5 showing postoperative pleural effusion (arrow). B, Roentgenography before the emergency thoracotomy showing an increase in the right pleural fluid level (arrow). C, Enhanced computed tomography scan showing the staple in contact with the segmental artery in front of the eighth thoracic vertebra (arrow).

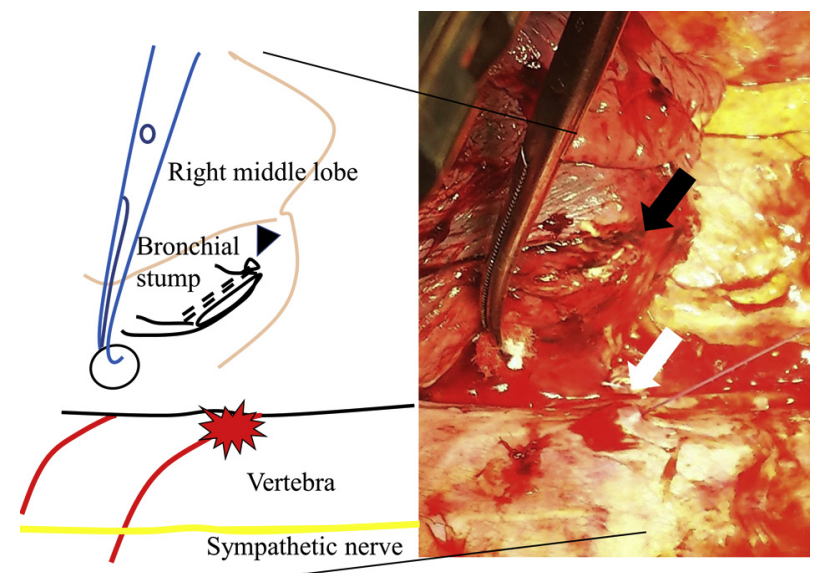

FIGURE 2. The bleeding point is a segmental artery in front of the eighth thoracic vertebra, which faces a stump of the right lower bronchus divided by the stapler. The white arrow indicates the bleeding point; black arrow, the bronchus stump; black arrowhead, protruding staples. parenchyma has been reported, ${ }^{2,3}$ delayed hemothorax due to bronchial staples, which is what we encountered, has not. In our case, the medial side edge of the stapling line was protruding from the bronchial stump and apparently eroded the pleura and eventually injured the artery. This problem might only occur with a lower lobectomy, because the right upper lobe or right middle lobe bronchial stumps generally would be forced anteriorly by the reexpanding remaining lobes, whereas the right lower lobectomy stump would be rotated posteriorly when the right upper lobe and middle lobe reinflated. Finally, in our case, bleeding occurred from the segmental artery in front of the eighth thoracic vertebra and eventually led to hemothorax.

Although bleeding due to staple injuries is rare during pulmonary resection involving bronchial stapling, caution is necessary while performing the stapling procedure. When the staple line comes in contact with the chest wall or a staple fails, the excessive projection of the staple may 
be trimmed or buttressed with autologous tissue such as pleura, the thymus should be considered when the postresection geometry suggests this as a potential issue.

\section{CONCLUSIONS}

Although the use of a stapler during thoracic surgery has been accepted as a reliable and safe procedure, careful attention must be given to the excessive projection of a staple during surgery. Our findings will help prevent complications during surgery and reduce the postoperative healing time.

\section{References}

1. Amosov NM, Berezovsky KK. Pulmonary resection with mechanical suture. $J$ Thorac Cardiovasc Surg. 1961;41:325-35.

2. Kanai Y, Endo S, Tetsuka K, Yamamoto S. Massive hemothorax after pulmonary endostapling preloaded with bioabsorbable tissue reinforcement material. Interact Cardiovasc Thorac Surg. 2012;14:345-6.

3. Motoyama H, Yamashita A, Chihara K. Sudden hemothorax following lobectomy caused by a staple. Interact Cardiovasc Thorac Surg. 2009;9:117-8.

4. Yano M, Yokoi K, Numanami H, Kondo R, Ohde Y, Sugaya M, et al. Complications of bronchial stapling in thoracic surgery. World J Surg. 2014;38:341-6.

5. Yano M, Numanami H, Akiyama T, Taguchi R, Furuta C, Haniuda M. Reoperation for postoperative bleeding following pulmonary resection: a report of a singlecenter experience. Gen Thorac Cardiovasc Surg. 2019;67:608-14. 